\title{
TRATAMENTO ANTIMICROBIANO DAS INFECÇÕES DO TRATO URINÁRIO EM CRIANÇAS
}

\author{
Antimicrobial treatment of urinary tract infections in children \\ Fernando de Sá Del Fiol ${ }^{1 *}$; Luciane Cruz Lopes ${ }^{2 ;}$ Ana Carolina Bôro ${ }^{3}$ \\ ${ }^{12}$ Mestrado em Ciências Farmacêuticas Universidade de Sorocaba, \\ Rod. Raposo Tavares, Km 92,5; Cep 18520-000; Sorocaba; \\ ${ }^{3}$ Farmacêutica, Especialista em Farmacologia - Rua Trajano Reis, 185. São Paulo, S.P.
}

•Autor para correspondência e-mail: fernando.fiol@uniso.br

Recebido em 21/02/2008 - Aceito em 12/12/2008

\begin{abstract}
RESUMO: As infecções do trato urinário (ITU) estão entre as mais comuns infecções bacterianas encontradas em crianças. Como essas infecções podem ter conseqüências em longo prazo, tais como insuficiência renal e hipertensão, tona-se importante tratar pacientes com ITU, precoce e adequadamente. A susceptibilidade da criança, a presença de anormalidades no trato urinário, como refluxo vesiculo-uretral, e a virulência do microrganismo são fatores de importância no desenvolvimento dessa infecção. O objetivo desse estudo foi formular recomendações para farmacêuticos sobre o diagnóstico, tratamento e avaliação de uma infecção urinária inicial em crianças febris e em jovens, com especial ênfase no uso racional de antibióticos. Nós revimos diversos protocolos para o tratamento de infecções urinárias e apresentamos com o objetivo de auxiliar profissionais da saúde em reconhecer e auxiliar crianças com infecções do trato urinário.
\end{abstract}

PALAVRAS-CHAVE: agentes anti-bacterianos, infecções urinárias, pediatria.

ABSTRACT: Urinary tract infections (UTIs) are among the most common bacterial infections encountered in children. As it may have long-term consequences such as kidney failure and hypertension, it is important to treat patients with UTI, early and adequately. The susceptibility of the child, the presence of urinary tract abnormalities, like vesicoureteral reflux and the microrganism virulence are factors of importance in the development of this infection. The objective of this study was to formulate recommendations for pharmacists about the diagnosis, treatment, and evaluation of an initial urinary tract infection (UTI) in febrile infants and young children, with special importance in antibiotics rational use. We reviewed several guidelines for UTI treatment and we present them aiming to help health professional to recognize and assist children with urinary tract infectionns.

KEYWORDS: anti-bacterial agents; urinary tract infections, pediatrics.

\section{INTRODUÇÃO}

As Infecções do Trato Urinário (ITU) estão cada vez mais acometendo crianças, desde seu período neonatal até a fase escolar. Um levantamento epidemiológico feito pelo Projeto Diretrizes da Associação Médica Brasileira e Conselho Federal de Medicina mostra que aproximadamente $2 \%$ das crianças do sexo masculino e $8 \%$ das crianças do sexo feminino apresentam ou já apresentaram esse tipo de infecção. A ITU caracteriza-se pela invasão e multiplicação de bactérias nos rins e vias urinárias, causando sintomatologia específica (FERNANDEZ, 2004). Podem acometer o trato urinário inferior (cistites e uretrites) e o trato superior, como os rins e a pelve renal (pielonefrites). Em alguns países, com fortalecimento do cronograma de imunização, o trato urinário é o local mais freqüente de infecção bacteriana grave na criança, superando a meningite e a pneumonia, em virtude da ausência de processos de imunização (FARHAT e KHOURY, 2004). 
O tratamento das ITU deve ser distinguido de acordo com a origem comunitária ou hospitalar do enfermo, a localização da infecção e se é complicada ou não. Um dos fatores de atenção à criança que apresenta infecção urinária tem sido não somente ao diagnóstico e ao tratamento, mas também a minimização do dano renal crônico e suas conseqüências clínicas. Assim, o principal objetivo da presente revisão bibliográfica é rever os principais protocolos terapêuticos empregados no tratamento ITU's em pediatria.

\section{Definição}

A infecção do Trato Urinário (ITU) é definida como um conjunto de alterações patológicas conseqüentes a multiplicações de bactérias no trato urinário. A área periuretral é colonizada por bactérias aeróbicas e anaeróbicas, onde o primeiro passo no desenvolvimento da infecção urinária é um distúrbio da microbiota normal e a colonização por cepas gram-negativas, principalmente a Escherichia coli. As cepas de E.coli uropatogênicas são populações selecionadas da bactéria que colonizam o intestino e expressam combinações de antígenos e fatores de virulência (KOCH e ZUCCOLOTTO, 2004).

A E.coli, sozinha, é responsável por $80 \%$ a $90 \%$ das infecções do trato urinário adquiridas na comunidade, contudo, o agente etiológico varia de acordo com a idade, sexo e as condições clínicas da criança. Várias outras bactérias podem estar envolvidas na gênese da ITU como Staphylococcus saprophyticus, Klebsiella pneumoniae, Proteus mirabilis, Pseudomonas aeruginosa, Enterococcus spp, Providencia spp, Serratia marcescens, Salmonella spp, Enterobacter spp, Staphylococcus aureus, dentre outras. Caracteriza-se como infecção urinária, o crescimento bacteriano de pelo menos $10^{5}$ unidades formadoras de colônias por $\mathrm{mL}$ de urina (100.000 ufc/mL) colhida em jato médio e de maneira asséptica (CARVALHÃES e ANDRADE, 2007).

Basicamente, a ITU é dividida em infecção urinária baixa infecção urinária alta. A infecção baixa é a invasão da uretra e bexiga, sendo denominada de cistite. A infecção alta é a invasão dos rins, denominada pielonefrite (MARINHO e TAVARES, 2005). Em relação à patogênese, a via ascendente é a principal forma de infecção das vias urinárias, por bactérias entéricas, sendo um dos fatores predisponentes para a mulher ser o indivíduo mais acometido pelas ITU, devido as suas características anatômicas, como uretra curta e sua maior proximidade com vagina e com o ânus. $\mathrm{Na}$ infância, as malformações das vias urinárias também se constituem como fator de importância.

A simples presença do microorganismo no trato urinário não configura obrigatoriamente a infecção, pois esta ocorre na dependência de outros fatores. A ocorrência dependerá de virulência do microorganismo, tamanho do inoculo, integridade dos mecanismos de defesa (locais e imunológicos), integridade anatômica e funcional do sistema urinário, presença de cateteres e constatação de infecção uretral prévia ou concomitante (MARINHO e TAVARES, 2005).

\section{Epidemiologia}

Estima-se que entre 7 e $8 \%$ das meninas e $2 \%$ dos meninos podem apresentar no mínimo um episódio de ITU na infância (KOCH e ZUCCOLOTTO, 2004; ALPER e CURRY, 2005). As crianças do sexo masculino são mais susceptíveis nos primeiros dois meses de vida, especialmente aqueles não circuncidados. Um estudo realizado no ano 2000 mostra que no primeiro ano de vida, a incidência de ITU em meninos não circuncidados foi de $2,15 \%$, para as meninas deu-se em torno de $2,05 \%$ e para os meninos circuncidados $0,22 \%$, ou seja, uma taxa de infecção aproximadamente 10 vezes maior para os não circuncidados (SCHOEN et al 2000). Em crianças do sexo masculino, o Proteus sp. é responsável pela colonização do prepúcio sendo isolado em $30 \%$ dos casos de ITU nos meninos(KOCH e ZUCCOLOTTO, 2004). A Escherichia coli é responsável por cerca de $80 \%$ das infecções em meninas e cerca de $40 \%$ nos meninos. A incidência de ITU aumenta nas meninas após o primeiro ano em função de características anatômicas que favorecem a colonização da uretra por microrganismos originários do intestino. Descreve-se uma distribuição trimodal em meninas: um primeiro caso no primeiro ano de vida, um segundo caso entre o segundo e o terceiro ano de vida e um último no início da vida sexual (BRAZ, 1999). Os prejuízos advindos de um diagnóstico tardio de ITU obrigam os profissionais da atenção primária à saúde à um elevado grau de suspeição quando se deparam com pacientes febris: a pielonefrite pode ser a causa e passar desapercebida no atendimento. Como motivo de consulta, a ITU é ultrapassada apenas pelas infecções do trato respiratório (FARHAT e KHOURY, 2004).

\section{Diagnóstico Clínico}

A infecção do trato urinário baixo (cistite), quando sintomática, exterioriza-se clinicamente pela presença habitual de disúria, urgência miccional, polaciúria, nictúria e dor suprapúbica. A febre pode ou não estar presente. A infecção do trato urinário alto (pielonefrite), que comumente se inicia como um quadro de cistite é habitualmente 
acompanhada de febre - geralmente superior a 38 graus centígrados, calafrios e de dor lombar, unilateral ou bilateral. Esta tríade febre + calafrios + dor lombar está presente na maioria dos quadros de pielonefrite (CAVALHÃES e ANDRADE, 2007). Não são raras as queixas por parte dos pais de corrimento vaginal em quadro de ITU em meninas, sendo a vaginite um fator predisponente de infecção urinária. Em meninos, o saco prepucial, colonizado por bactérias, desenvolve um quadro de postite podendo evoluir para um quadro mais intenso de disúria, saída de secreção purulenta e sinais de inflamação localizada, o qual pode preceder uma infecção urinária (BRAZ, 1999).

Mesmo quando o estado febril não está evidenciado, os sintomas de disúria e polaciúria chamam a atenção para o diagnóstico de infecção urinária. $O$ aspecto da urina pode também trazer informações valiosas: urina turva (pela presença de piúria) e/ou avermelhada (pela presença de sangue, causada por cálculo e/ou pelo próprio processo inflamatório) (MARINHO e TAVARES, 2005).

$\mathrm{Na}$ criança é difícil a coleta da primeira urina do dia, por isso, valoriza-se qualquer amostra desde que haja um intervalo mínimo de 2 horas entre as micções. Este intervalo é imprescindível para o crescimento bacteriano mínimo, reduz exames falsos negativos. Recomenda-se que o material coletado seja semeado de imediato em meio seletivo para bactérias gram negativas e em meio de cultura rico. É necessária incubação de 24 horas para contagem de colônias e um tempo de 12 a 24 horas a mais para a identificação do agente e a realização do teste de antibiograma. O número de colônias necessário para se considerar uma cultura positiva é de $10^{5} \mathrm{ufc} / \mathrm{mL}$ em crianças (OKUMURA, 2004).

\section{Diagnóstico Laboratorial}

A avaliação da infecção urinária deve ser feita através da análise da urina. Deve-se investigar a presenças de bactérias e a leucocitúria e, também, a presença de outros fatores como $\mathrm{pH}$, presença de nitrito, estearase leucocitária, hemoglobina e a presença de piócitos. O isolamento da bactéria causadora é fundamental para a caracterização de ITU e seu isolamento (BRAZ, 1999).

Para se realizar uma urocultura adequada destacam-se quatro principais métodos de coleta de urina: bolsa plástica adaptada à região perineal, micção espontânea com coleta de jato médio, cateterismo uretral e punção suprapúbica. Os exames preferidos dependem da idade da criança. A Academia Americana de Pediatria recomenda que a urina de pacientes febris de dois meses a 2 anos de idade seja coletada por métodos invasivos (punção suprapúbica e cateterização uretral), em crianças do sexo feminino e naquelas do sexo masculino não circuncisadas, uma vez que nesses casos a coleta por saco coletor apresenta alto grau de contaminação. Para crianças maiores que já possuem um controle de micção, a coleta do jato médio é uma maneira fácil e prática devendo, é claro, serem tomadas medidas de higiene para a coleta, como a assepsia adequada, utilização de frascos estéreis e armazenamento para maior garantia da especificidade (AMERICAN ACADEMY OF PEDIATRICS, 1999).

Os exames laboratoriais para análise da urina são basicamente:

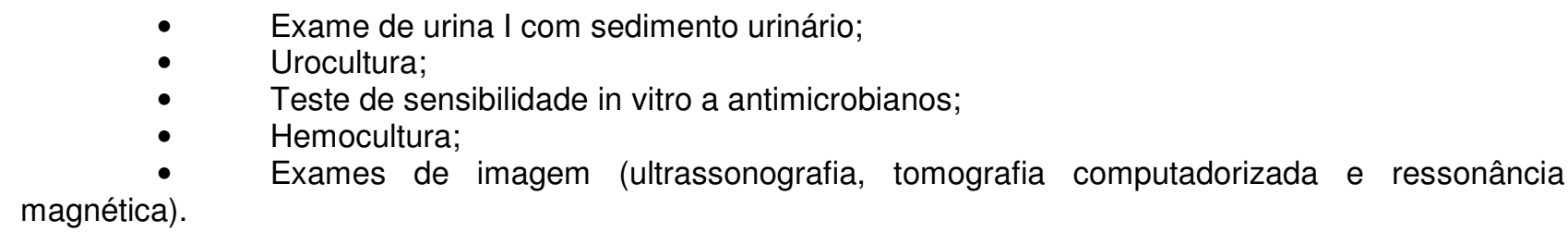

Obrigatório em ambos os sexos após o primeiro episódio de infecção urinária febril confirmada, a investigação por imagem pode minimizar uma conseqüente lesão renal (AMERICAN ACADEMY OF PEDIATRICS, 1999).

\section{Tratamento}

O objetivo do tratamento da infecção urinária na criança, no primeiro episódio, é o alívio do quadro sintomático do paciente e, principalmente, a preservação do trato urinário superior, minimizando o aparecimento de lesões cicatriciais do parênquima renal. Ele depende da idade da criança e de severidades do quadro. É aconselhável, sempre que possível a antibioticoterapia, ser baseada no antibiograma realizado com uma amostra de urina do paciente (CARVALHÃES e ANDRADE, 2007). O início do tratamento não deve ser retardado e a terapêutica empírica deve ser instituída após a coleta da urina para os exames já citados. 
Após 72 horas do início da antibioticoterapia, se a resposta clínica não for adequada, faz-se nova avaliação com coleta de urina tipo I e urocultura, e troca-se o antibiótico conforme o resultado da sensibilidade bacteriana. Nestes casos, deve-se sempre pensar na possibilidade da resistência bacteriana, na infecção por agentes menos comuns, como o Proteus e na existência de anomalias do trato urinário. A escolha do agente a ser empregado empiricamente deve levar em consideração: sensibilidade local/regional frente aos microrganismos frequentemente encontrados; farmacocinética adequada, com excreção renal in natura do fármaco eleito; baixa toxicidade celular e pouca alteração na microbiota intestinal (MACEDO et al., 2006).

Com relação à via empregada, deve-se dar preferência, nas ITU não complicadas, para o tratamento comunitário com medicação por via oral. A presença da criança no hospital com acesso venoso, além de trazer angustia e ansiedade para ela e para os pais, aumenta a probabilidade de novas infecções e contaminações pelo acesso venoso. Deve-se reservar a via parenteral para situações de risco, para pacientes com incapacidade de deglutição ou vômitos e para microrganismos resistentes (CRAIG e HODSON, 2004).

A duração da terapia empregada nesses casos tem sido motivo para um grande número de estudos que têm mostrado, com certa concordância, que terapêuticas de curso curto; 1 a 3 dias, não tem sido tão eficazes quanto antibioticoterapias tradicionais (7 a 10 dias ou até 14 dias) (MADRIGAL, et al., 1988; NOLAN et al, 1989).

Para estabelecermos uma terapêutica antimicrobiana eficaz, deve-se levar em conta a sensibilidade do patógeno associado, a farmacocinética do antibiótico empregado e especialmente em pedatria, a segurança do fármaco. Em vista disso os protocolos empregados em adultos devem ser revisitados com essa preocupação - a da segurança. (DEL FIOL e AVALLONE, 2005)

Em virutde da pequena toxicidade celular direta, os beta-lactâmicos como a amoxicilina e cefalexina são sempre lembrados como os fármacos de primeira escolha em pediatria. Entretanto, temos acompanhado um aumento significativo dos índices de resistência da E.coli à esses fármacos, o que nos leva a considerar outras opções, como sua associação ao ácido clavulânico ou ainda outras classes químicas como as sulfas (JOSEPH et al., 2005). Em trabalhos recentes, os índices de resistência aos antimicrobianos mais empregados em infecções urinárias foram avaliados frente ao patógeno mais associado nessas infecções, a E.coli. As taxas de resistência à ampicilina estiveram entre 39 e $45 \%$, à sulfametoxazol mais trimetoprima entre 14 e $31 \%$, para nitrofurantoína, entre 1,8 a $16 \%$ e finalmente para as fluoroquinolonas entre 0,7 e 10\% (RICCABONA, 2003). Deve-se lembrar que o mecanismo de ação dos beta-lactâmicos envolve a interferência na síntese da parede celular com consequente entrada de água e lise celular. Para tanto, o consumo aumentado de líquidos durante a vigência do tratamento com esses fármacos, aumentará a diferença osmótica entre a bactéria e o meio, favorecendo a entrada de água na bactéria, incrementando a ação antibiótica. A oferta hidriva ainda diminui a possibilidade de distúrbios hidroelétrolíticos, assegurnado uma diurese profusa. Em crianças com condição de compreensão e autonomia urinária, é fundamental a orientação para micções freqüentes, diminuindo a urina retida, ótimo meio de cultura para microrganismos oportunisitas (CARVALHAES e ANDRADE, 2007)

As sulfas e a nitrofurantoína foram objeto de amplo estudo que avaliou a toxicidade desses fármacos em crianças com infecções urinárias. As reações encontradas limitaram-se a manifestações cutâneas e gastrointestinais. Os autores concluem que ambos os fármacos podem ser utilizados em pediatria com grande segurança (KARPMAN e KURZROCK, 2004).

As fluoroquinolonas têm sido extensamente utilizadas em adultos, com altos índices de cura e sem relatos de toxicidade. A utilização em crianças ainda não é consenso, mas tem sido empregada com bastante sucesso apesar de sua segurança ainda não estar completamente estabelecida (KOYLE et al., 2003)

As tabelas 1 e 2 mostram os tratamentos empregados para a infecção do trato urinário em crianças (SOCIEDADE DE PEDIATRIA DE SÃO PAULO, 2002; JOSEPH et al, 2005; ALPER \& CURRY, 2006).

Tabela 1. Fármacos e doses mais utilizados (via oral) para tratamento de ITU em crianças

\begin{tabular}{|c|c|c|}
\hline Fármaco & $\begin{array}{c}\text { Dose } \\
\text { (mg/Kg/dia) }\end{array}$ & $\begin{array}{c}\text { Número de } \\
\text { tomadas diárias }\end{array}$ \\
\hline
\end{tabular}

Comentários

Amoxicilina $\quad 20$ a 40

3

Segura, resistência crescente. Pode ser associada ao ácido clavulânico

Cefalexina

50 a 100

4

Alergia cruzada à penicilina, intefere com a microbiota intestinal 


\begin{tabular}{cccc}
\hline $\begin{array}{c}\text { Sulfametoxazol + } \\
\text { Trimetoprima }\end{array}$ & $8-10$ & 2 & $\begin{array}{c}\text { Comodidade posológica. Não usar em } \\
\text { recém nascidos (icterícia) }\end{array}$ \\
Nitrofurantoína & 5 & 4 & $\begin{array}{c}\text { Não utilizar em pielonefrites (pouca } \\
\text { penetração tecidual) }\end{array}$ \\
\hline
\end{tabular}

Tabela 2. Fármacos e doses mais utilizados (via parenteral) para tratamento de ITU em crianças.

\begin{tabular}{cccc}
\hline Fármaco & $\begin{array}{c}\text { Dose } \\
(\mathbf{m g} / \mathbf{K g} / \mathbf{d i a})\end{array}$ & $\begin{array}{c}\text { Número de } \\
\text { tomadas } \\
\text { diárias }\end{array}$ & Comentários \\
\hline Ciprofloxacino & 10 a 20 & 3 & Não utilizar em crianças menores de 18 meses \\
Ceftriaxona & 50 a 100 & 1 & Hipersensibilidade, oto e nefrotoxicidade \\
\hline
\end{tabular}

A terapêutica parenteral deve ser reservada para crianças que, por qualquer motivo, não podem fazer a utilização por via oral; quando houver necessidade de altas concentrações ou para o tratamento de microrganismos específicos determinados no antibiograma. A terapêutica deve ser instituída e empregada por todo o tempo prescrito, pois os índices de insucesso terapêutico e de resistência bacteriana são cada vez maiores (TORRES E MARTINS, 2005).

Após estabelecida a cura, é fundamental o acompanhamento para se evitar recidivas. Entre 30 e $50 \%$ dos meninos com ITU apresentam recidivas após os seis primeiros meses do tratamento (CARVALHÃES e ANDRADE, 2007).

Em crianças com presença confirmada de refluxo vesículo-uretral (RVU) ou com mais de três casos/ano, há a recomendação para a quimioprofilaxia com antimicrobianos em baixas doses. A nitrofurantoína é utilizada como fármaco de primeira escolha, na doses de $1 \mathrm{mg} / \mathrm{Kg} / \mathrm{dia}$ em dose única noturna. Como substituto, pode-se utilizar o ácido nalidíxico, de 15 a $20 \mathrm{mg} / \mathrm{Kg} / \mathrm{dia}$, também em dose única noturna, ou ainda a sulfametoxazol + trimetoprima na dose de $2 \mathrm{mg} / \mathrm{Kg} / \mathrm{dia}$. (SOCIEDADE DE PEDIATRIA DE SÃO PAULO, 2002) Nesses casos há a necessidade de controle mensal de urina tipo I e urocultura. Nos primeiro meses de vida, a utilização do ácido nalidíxico está contra-indicada (DAL BEN e CARVALHÃES, 2001)

\section{CONCLUSÕES}

As infecções do trato urinário vêm acometendo cada vez mais crianças, e apesar do diagnóstico e todo arsenal terapêutico, depara-se corriqueiramente com infecções recorrentes, causados pelo insucesso terapêutico, pelo diagnóstico tardio e por hábitos de higiene que favorecem a recorrência e ainda por malformações do trato urinário. O profissional farmacêutico deve estar preparado para reconhecer uma infecção urinária, fazer a adequada orientação e conhecer com profundidade a terapêutica adotada nesses casos.

É fundamental que o profissional conheça os efeitos colaterais mais significativos para cada um dos fármacos elencados para a terapêutica e as opções nas situações especiais, como resistência ou recorrência. Importante salientar que inúmeros casos são recorrentes e é também seu papel buscar informações com o paciente tentando identificar os fatores de risco envolvidos na recorrência.

\section{REFERÊNCIAS BIBLIOGRÁFICAS}

ALPER, B.S.; CURRY, S.H. Urinary tract infection in children. American Family Physician. v. 72, n.12, p. 2483-8, 2005.

BRAZ, M.P. Infecção urinária na infância. Urologia Pediátrica. v.3, p.16-20, 1999. 
CARVALHÃES, J.T.A.; ANDRADE, M.C. Infecção urinária na infância. In PRADO, F.C.; RAMOS, J.; VALLE, J.R. Atualização Terapêutica 2007. São Paulo: Artes Médicas, 2007.

Committee on Quality Improvement and Subcommittee on Urinary Tract Infection. Practice Parameter: The diagnosis, Treatment, and Evaluation of the Initial Urinary Tract Infection in Febrile Infants and Young Children. Pediatrics. v.103, n.4, p. 843-52, 1999.

CRAIG, J.C.; HODSON, E.M. Treatment of acute pyelonephritis in children British Medical Journal. v.328, p.179180, 2004.

DAL BEN, G.L.; CARVALHÃES, J.T.A. Infecção do trato urinário. In CARVALHO, E.S.; CARVALHO, W.B. Terapêutica e Prática Pediátrica. São Paulo: Artes Médicas, 2001.

DEL FIOL, F.S.; AVALLONE, A.M. Uso de Cloranfenicol na Gestação Revista Eletrônica de Farmácia. v.2, n.1,p 31-37, 2005.

FARHAT W.; KHOURY A. Constipação e infecção do trato urinário. Urologia Pediátrica v.1, p. 275-283, 2004.

FERNANDEZ, E. Abordagem da criança com infecção urinária. Revista Portal Clínica Geral. v. 20, p. 669-78, 2004.

KARPMAN, E.; KURZROCK, E.A. Adverse reactions of nitrofurantoin, trimethoprim and sulfamethoxazole in children. Journal of Urology. v.172, n. 2, p.448-453, 2004.

KOCH, V.H.; ZUCCOLOTTO, S.M.C. Infecção do trato urinário: em busca das evidências. Jornal de Pediatria. v.79, n.I.1, p.S97-S106, 2003.

KOYLE, M. A.; et al. Pediatric urinary tract infections: the role of fluoroquinolones. Pediatric Infectious Diseases Journal, v. 22, n. 12, p.1133-1137, 2003.

MACEDO, C.S.; RIYUZO, M.C.; BASTOS, H.D. Infecção do trato urinário. In: Departamento de Pediatria, Faculdade de Medicina de Botucatu. (Org.). Pediatria Clínica. Rio de Janeiro: EPUB, v.1, p.509-512, 2006.

MADRIGAL G.; et al. Single dose antibiotic therapy is not as effective as conventional regimens for management of acute urinary tract infections in children. Pediatric Infectious Diseases Journal. v. 7, n.5, p.316-319, 1988.

MARINHO, L.A.C; TAVARES, W. Infecção Urinária. Rotinas de diagnósticos e tratamento de doenças Infecciosas e parasitárias. São Paulo: Atheneu, 2005.

NOLAN, T.; LUBITZ, L.; OBERKLAID, F. Single dose trimethoprim for urinary tract infection. Archives of Disease in Childhood, v. 64, n.4, p.581-6, 1989.

OKUMURA, A. Infecção do Trato Urinário (ITU). Manual de Condutas Médicas, Departamento de Pediatria, Faculdade de Medicina da Bahoa da Universidade Federal da Bahia, p.161-164, 2004.

RICCABONA, M. Urinary tract infections in children. Current Opinion in Urology, n.13, n. 1, p. 59-62, 2003.

SCHOEN, E.J.; COLBY, C.J.; RAY, J.T. Newborn circumcision decreases incidence an costs of urinary tract infections during the first year of life. Pediatrics; v. 105, p.789-93, 2000.

Sociedade de Pediatria de São Paulo: Tratamento da infecção do trato urinário na infância. Recomendações Atualização de Condutas em Pediatria, 2002.

TORRES, I.M.S., et al. Avaliação do Efeito Antimicrobiano In Vitro de Cefalosporinas em Lipossomas Unilamelares Revista Eletrônica de Farmácia Suplemento. v. 2, n.2, p. 218-220, 2005. 
ZORC, J. J.; KIDDOO, D. A.; SHAW, K. N. Diagnosis and Management of Pediatric Urinary Tract Infections. Clinical Microbiology Reviews, v. 18, n. 2, p. 417-422, 2005. 